\title{
Overweight among Four-Year-Old Children in Relation to Early Growth Characteristics and Socioeconomic Factors
}

\author{
Jörgen Thorn, ${ }^{1}$ Maria Waller, ${ }^{1}$ Maria Johansson, ${ }^{1}$ and Staffan Mårild ${ }^{2}$ \\ ${ }^{1}$ Sahlgrenska School of Public Health and Community Medicine, Section of Primary Health Care, University of Gothenburg, \\ Box 454, 40530 Gothenburg, Sweden \\ ${ }^{2}$ The Queen Silvia Children's Hospital, Göteborg, Paediatric Growth Research Centre, Department of Paediatrics, \\ The Sahlgrenska Academy at University of Gothenburg, Smörslottsgatan, 41685 Gothenburg, Sweden
}

Correspondence should be addressed to Staffan Mårild, staffan.marild@pediat.gu.se

Received 9 November 2009; Accepted 5 January 2010

Academic Editor: Alfredo Halpern

Copyright ( $\odot 2010$ Jörgen Thorn et al. This is an open access article distributed under the Creative Commons Attribution License, which permits unrestricted use, distribution, and reproduction in any medium, provided the original work is properly cited.

Objectives. To assess early growth characteristics and socioeconomic factors of children in relation to body mass index (BMI) and presence of overweight among four-year-old children. Methods. Two Child Health Centres (CHC) participated in the study. They were selected to obtain two populations of children featuring divergent socio-economic characteristics. Growth data registered at the CHCs from birth to the 4-year check-up were recovered. Overweight was defined by the BMI cut-offs established by IOTF. BMI values expressed as BMI standard deviation score (BMISDS) were used for analysis. Results. At the 4-year check-up, the BMISDS and the proportion of children with overweight (including the obese) were significantly higher in the district with lower socio-economic status. High BMI at birth and low socio-economic status of the population in the CHC-district were shown to be independent determinants for overweight and BMISDS at four years of age. Conclusions. More research is needed to understand the mechanisms and how intervention programs should be designed in order to prevent the development of overweight and obesity in children.

\section{Introduction}

The global epidemic of overweight and obesity and its health consequences are a worldwide concern [1]. A dramatic increase in the prevalence of obesity and overweight among children and adolescents has occurred during the last three decades in most parts of the world [2]. An increase in the prevalence of overweight and obesity has also been demonstrated in Swedish school-aged children [3]. There are, however, only a few studies concerning the development of overweight among preschool children [4].

Overweight children run an increased risk to become obese as children and also overweight/obese as adults [5]. A child with obesity is at risk to develop a wide spectrum of adiposity-related diseases and comorbid conditions. Psychosocial problems, diabetes mellitus, and cardiovascular diseases are associated with obesity, as well as liver disease, sleep apnoea, cancers, and orthopaedic disorders [6]. Insulin resistance is often seen in individuals with obesity and is of special concern due to its central role in the pathogenesis of several obesity-associated diseases [7]. The insulin-resistance syndrome has been shown to be present in a large proportion of children with overweight or obesity [8]. Learning the mechanisms and determinants behind the variation in the prevalence of obesity in different populations is required for the development of effective preventive interventions. Socioeconomic, genetic, and environmental factors are involved [9].

Since preventive interventions preferably should start in early life, studies in preschool children are of particular interest. The Primary Health Care has a key role in this aspect as the General Practitioner (GP) and the GP staff can identify and target families at risk for lifestyle-induced morbidity in their children and adolescents [10]. In particular, the identification of obese children in health screening programs has been shown to have a preventive potential [11].

The purpose of the study was to assess early growth characteristics and Socioeconomic factors of children in relation to body mass index (BMI) and presence of overweight among four-year-old children examined at Child Health Centres $(\mathrm{CHC})$. 


\section{Materials and Methods}

In Sweden, all preschool children, with rare exceptions, are registered and attend health check-ups at their local CHC. In the child health records, the children's growth data are recorded from birth and onwards. Newborns are measured by trained midwives at the delivery room, using standard methods, and these data on neonatal weight and supine length are reported on special forms to the CHC and placed in child health records [12]. After birth, specialised pediatric nurses are responsible for repeated consecutive health screenings of the children living within a certain area. Participation of children at the local CHC is nearly $100 \%$ among the children living in the area. The check-ups also include monitoring of growth and registrating growth data in the child health record. Height is measured to the nearest $0.5 \mathrm{~cm}$ with a standard stadiometer with the child in standing position. Weight is measured with the child in light clothing to the nearest 0.1 kilogram on an electronic scale, which is calibrated at regular intervals. In addition to growth data, information on other variables, such as duration of breastfeeding and maternal smoking, is obtained from the parents and registered in the records during the consecutive health check-ups. At four years of age, an important checkup is scheduled routinely for all the children registered at the $\mathrm{CHC}$.

In the present study, overweight was defined by using the BMI cut-offs established by IOTF [13]. The individual BMI values were also converted to a BMI standard deviation score (BMISDS) or z-score using a reference population from Gothenburg as described by Karlberg et al. [14, 15]. "highgrowth velocity children" were defined as those having a change in weight of more than $16 \mathrm{~kg}$ (upper quartile) from birth until four years of age.

Children from two CHC were analysed in the study. The CHCs were selected in order to obtain two populations featuring dissimilar Socioeconomic characteristics. The demografic- and Socioeconomic factors of the districts are presented in Table 1 [16]. In district A (dA), significantly more inhabitants were born abroad and were unemployed compared to district B (dB). Also fewer subjects had completed 12 years of school education or had university degrees in $\mathrm{dA}$ than in $\mathrm{dB}$. Furthermore, in $\mathrm{dA}$, the income level was lower and the "unhealthy rate" was higher. Unhealthy rate was defined as the yearly number of work days payed by the social insurance system divided with the number of inhabitants in the area (16-64 years of age).

In $\mathrm{dA}$, all 90 4-year-old children were invited for the regular check-up at the local CHC (CHC-dA). Of these, 85 (94\%) accomplished the check-up. All drop-outs were girls. Similarly, in $\mathrm{dB}$, all 234 children were invited for a checkup (CHC-dB). Of these, 224 (96\%) children participated. Of the drop-outs, seven were girls and three were boys. The data were collected from both CHCs in 2006.

2.1. Statistical Analysis. Descriptive statistics was used for prevalence data. For comparison between CHC-dA and CHC-dB groups, Fisher's exact test was used for dichotomous variables, two sample $t$-tests for normally distributed
Table 1: Demografic- and Socioeconomic characteristics of the populations in the two districts.

\begin{tabular}{lccc}
\hline & District A (dA) & District B (dB) & $P$-value \\
\hline $\begin{array}{l}\text { Number of } \\
\text { inhabitants }\end{array}$ & 27163 & 19909 & \\
$\begin{array}{l}\text { Inhabitants born } \\
\text { abroad, } n(\%)\end{array}$ & $2321(8.5)$ & $929(4.6)$ & $<.0001$ \\
$\begin{array}{l}\text { Unemployment, } n \\
(\%)\end{array}$ & $1062(3.9)$ & $534(2.7)$ & $<.0001$ \\
$\begin{array}{l}\text { Index for } \\
\text { "unhealthy rate" }\end{array}$ & 51.4 & 23.2 & $*$ \\
$\begin{array}{l}\text { Higher education } \\
\text { (>12 years), } n(\%)\end{array}$ & $2865(10.5)$ & $4794(24.1)$ & $<.0001$ \\
$\begin{array}{l}\text { Income (Mean, } \\
\text { Swedish Crowns } \\
\text { per year) }\end{array}$ & 177000 & 256000 & $*$ \\
$\begin{array}{l}\text { Inhabitants on sick } \\
\text { leave for more than } \\
\text { one year, } n \text { (\%) }\end{array}$ & $2330(8.6)$ & $768(3.8)$ & $<.0001$ \\
\hline $\begin{array}{l}* \\
\text { P-value could not be estimated since only mean values were available and }\end{array}$ \\
not the distributions.
\end{tabular}

and Mann-Whitney test for nonnormally distributed variables. Pearson correlation analyses were performed between BMISDS at 4 years of age and possible predictor variables. Analysis of covariance was used to adjust for length, weight, and BMI at birth in comparisons of BMISDS between the $\mathrm{CHC}-\mathrm{dA}$ and $\mathrm{CHC}-\mathrm{dB}$ groups. Linear multiple regression analysis was performed to assess the determinants for BMISDS at 4 years of age. Stepwise logistic regression analyses were computed in a multivariate regression model with results presented as odds ratios (OR) with 95\% confidence intervals (CI). In this model, overweight (including obesity) at four years of age was the dependant variable, and CHC-district (proxy for Socioeconomic characteristics), dichotomised birth weight (median $3.52 \mathrm{~kg}$ ), birth length (median $0.51 \mathrm{~m}$ ), and BMI at birth (median $13.63 \mathrm{~kg} / \mathrm{m}^{2}$ ) were predictors. Differences were considered statistically significant at $P<.05$.

The Ethics Committee of the Faculty of Medicine at University of Gothenburg was contacted, and they gave their approval to the study without any formal application since the study were exclusively done on CHC-registered data.

\section{Results}

The prevalence of overweight and obesity among all the fouryear-old children from the two CHCs together $(n=309)$ was $14.3 \%$ and $3.2 \%$, respectively. A significantly higher proportion of children with overweight including obesity was present in CHC-dA as compared with CHC-dB $(P=.03$, Table 2). Furthermore, in CHC-dA there were significantly more children with a high-growth velocity rate (i.e., a change in weight above $16 \mathrm{~kg}$ (upper quartile) between birth and four years of age). The BMISDS at 4 years of age was also significantly higher in CHC-dA than in CHC-dB. Since the BMISDS at 4 years of age correlated to weight $(r=0.24$, $P<.0001)$, length $(r=0.1, P=.08)$, and BMI at birth 
TABLE 2: Variables obtained from the child health records at the two Child Health Centres in District A (CHC-dA) and District B (CHC-dB).

\begin{tabular}{|c|c|c|c|}
\hline & $\mathrm{CHC}-\mathrm{dA}$ & $\mathrm{CHC}-\mathrm{dB}$ & $P$-value \\
\hline Number & 224 & 85 & \\
\hline Boys, $n(\%)$ & $116(51.8)$ & $47(55.3)$ & n.s \\
\hline Girls, $n(\%)$ & $108(48.2)$ & $38(44.7)$ & \\
\hline \multicolumn{4}{|l|}{ Birth weight (kg) } \\
\hline $\operatorname{Mean}(\mathrm{SD})$ & $3.50(0.50)$ & $3.56(0.55)$ & n.s \\
\hline Range & 2.10 to 4.99 & 1.95 to 5.14 & \\
\hline \multicolumn{4}{|l|}{ Birth length (m) } \\
\hline $\operatorname{Mean}(\mathrm{SD})$ & $0.50(0.02)$ & $0.51(0.02)$ & n.s. \\
\hline Range & $0.43-0.61$ & $0.44-0.56$ & \\
\hline \multicolumn{4}{|l|}{ BMI at birth $\left(\mathrm{kg} / \mathrm{m}^{2}\right)$} \\
\hline $\operatorname{Mean}(\mathrm{SD})$ & $13.7(1.34)$ & $13.7(1.43)$ & n.s \\
\hline Range & 9.1 to 18.6 & 8.8 to 18.3 & \\
\hline \multicolumn{4}{|l|}{ Weight at the 4 years check-up (kg) } \\
\hline $\operatorname{Mean}(\mathrm{SD})$ & $18.1(2.68)$ & $17.8(2.14)$ & n.s \\
\hline Range & 11.6 to 28.5 & 13.5 to 26.8 & \\
\hline \multicolumn{4}{|l|}{ Height at the 4 years check-up (m) } \\
\hline Mean(SD) & $1.05(0.05)$ & $1.06(0.03)$ & n.s \\
\hline Range & 0.9 to 1.2 & 1.0 to 1.1 & \\
\hline \multicolumn{4}{|l|}{ BMI at the 4 years check-up $\left(\mathrm{kg} / \mathrm{m}^{2}\right)$} \\
\hline $\operatorname{Mean}(\mathrm{SD})$ & $16.2(1.61)$ & $15.8(1.32)$ & .08 \\
\hline Range & 13.4 to -23.1 & 12.9 to 21.4 & \\
\hline \multicolumn{4}{|l|}{ Change in weight from birth $(\mathrm{kg})$} \\
\hline $\operatorname{Mean}(S D)$ & $14.6(2.55)$ & $14.2(1.99)$ & n.s \\
\hline Range & 9.2 to 24.7 & 9.7 to 23.4 & \\
\hline \multicolumn{4}{|l|}{ Change in BMI from birth $\left(\mathrm{kg} / \mathrm{m}^{2}\right)$} \\
\hline $\operatorname{Mean}(\mathrm{SD})$ & $2.5(1.86)$ & $2.1(1.61)$ & .05 \\
\hline Range & -2.0 to 11.2 & -2.2 to 7.1 & \\
\hline \multicolumn{4}{|l|}{ Overweight at the 4 year check-up } \\
\hline Number $(\%)$ & $45(20)$ & $8(9)$ & .03 \\
\hline \multicolumn{4}{|l|}{ Obesity at the 4 year check-up } \\
\hline Number (\%) & $9(4)$ & $1(1)$ & n.s \\
\hline \multicolumn{4}{|l|}{ high-growth velocity children } \\
\hline Number (\%) & $58(20)$ & $11(13)$ & .01 \\
\hline \multicolumn{4}{|l|}{ BMISDS at 4 years of age } \\
\hline $\operatorname{Mean}(S D)$ & $0.14(1.20)$ & $-0.18(1.11)$ & .03 \\
\hline Range & -2.7 to 3.8 & -3.4 to 3.5 & \\
\hline Smoking rate among mothers during pregnancy $\%$ & 12 & 5 & .07 \\
\hline \multicolumn{4}{|l|}{ Duration of breastfeeding from birth (months) } \\
\hline $\operatorname{Mean}(S D)$ & $8(5.3)$ & $8.5(5.1)$ & n.s \\
\hline Range & 0 to 42 & 0 to 30 & \\
\hline
\end{tabular}

-BMI: Body Mass Index, - BMISDS: BMI standard deviation score or z-score, - high-growth velocity children: children with an increase in weight $>16 \mathrm{~kg}$ (upper quartile) from birth until four years of age.

$(r=0.27, P<.0001)$, an analysis was performed using these variables as covariates. The adjusted mean BMISDS was 0.16 and -0.20 for CHC-dA and $\mathrm{CHC}-\mathrm{dB}$, respectively, with an adjusted mean difference of -0.35 (95\% CI -0.64 to -0.07 , $P<.0001)$. In addition, there was a nonsignificant tendency
$(P=.07)$ for a higher proportion of maternal smoking during pregnancy in $\mathrm{CHC}-\mathrm{dA}$ as compared with $\mathrm{CHC}-\mathrm{dB}$. The breastfeeding rate did not differ between the districts.

The determinants for BMISDS at 4 years of age were studied in a linear multiple regression model. In this model, 
TABLE 3

(a) Analysis of continuous variables as predictors for body mass index standard deviation score (BMISDS): univariate correlations and outcomes of linear multiple regression analysis for the model BMISDS $=\mathrm{CHC}$, birth weight and birth BMI.

\begin{tabular}{lccc}
\hline & \multicolumn{3}{c}{ BMISDS } \\
\hline & $\begin{array}{c}\text { Univariate } \\
=R \text {-value }\end{array}$ & $P$-value & $\begin{array}{c}\text { Beta-value at } \\
\text { linear multiple } \\
\text { regression } \\
\text { analysis }\end{array}$ \\
\hline CHC & $0.12^{*}$ & .03 & 0.35 \\
$\begin{array}{l}\text { Birth weight } \\
\text { Birth length }\end{array}$ & $0.24^{*}$ & $<.001$ & $\mathrm{Ns}$ \\
$\begin{array}{l}\text { Birth BMI } \\
\text { Smoking rate of } \\
\text { mothers during } \\
\text { pregnancy }\end{array}$ & - & .08 & - \\
$\begin{array}{l}\text { Duration of } \\
\text { breastfeeding }\end{array}$ & - & $<.001$ & 0.18 \\
\begin{tabular}{l} 
Gender \\
\hline
\end{tabular} & - & Ns & \\
\hline L & - & Ns & \\
\hline
\end{tabular}

*included in multiple linear regression model

(b) Analysis of categorical variables as predictors for overweight at 4 years of age: results of a stepwise multiple logistic regression analysis for the model overweight (including the obese) $=$ dichotomised $\mathrm{CHC}$ and birth BMI.

\begin{tabular}{lccc}
\hline \multicolumn{4}{c}{ Overweight (including the obese) } \\
\hline & \multicolumn{4}{c}{ Stepwise logistic regression analysis } \\
\hline OR & $95 \%$ CI & $P$-value \\
CHC-dA = 2 & 2.6 & $1.2-5.8$ & .02 \\
CHC-dB = & - & - & - \\
Birth weight & - & - & - \\
Birth length & 1.9 & $1.1-3.6$ & .03 \\
Birth BMI** & & & - \\
& & & - \\
\hline
\end{tabular}

*included in multiple linear regression model OR: Odds Ratio CI: Confidence Intervals ${ }^{* *}$ Birth BMI: Dichotomised at the median $\left(13.6 \mathrm{~kg} / \mathrm{m}^{2}\right)$

BMI at birth and CHC-district were found to be significant independent determinants for BMISDS at 4 years of age (Table 3). In a stepwise logistic model, CHC-district and the $\mathrm{BMI}$ at birth were also significant independent determinants for overweight (including the obese) at the 4 years check-up.

In Table 4, the data of all the 4-year-old children in the two populations are presented jointly comparing all overweight and nonoverweight subjects (including the obese). The children that were overweight at four years of age had a significantly higher BMI and weight at birth, but their length at birth did not differ from the nonoverweight subjects. The table illustrates that BMI at birth was an independent determinant for development of overweight in the statistical
TABLE 4: BMI, length and weight at birth as well as height at four years of age for children with and without overweight (including the obese).

\begin{tabular}{|c|c|c|c|}
\hline & $\begin{array}{c}\text { No overweight* } \\
\quad N=255\end{array}$ & $\begin{array}{c}\text { Overweight* } \\
\qquad N=54\end{array}$ & $P$-value \\
\hline \multirow{3}{*}{ BMI at birth } & Mean 13.61 & Mean 14.06 & .02 \\
\hline & $\mathrm{M}: \mathrm{n} 13.54$ & $\mathrm{M}: \mathrm{n} 14.08$ & \\
\hline & SD 1.36 & SD 1.35 & \\
\hline \multirow{3}{*}{ Length at birth } & Mean 0.50 & Mean 0.51 & .2 \\
\hline & $\mathrm{M}: \mathrm{n} 0.51$ & $\mathrm{M}: \mathrm{n} 0.51$ & \\
\hline & SD 0.02 & SD 0.02 & \\
\hline \multirow{3}{*}{ Weight at birth } & Mean 3.49 & Mean 3.67 & .04 \\
\hline & $\mathrm{M}: \mathrm{n} 3.49$ & M : n 3.63 & \\
\hline & SD 0.50 & SD 0.57 & \\
\hline \multirow{3}{*}{$\begin{array}{l}\text { Height at } 4 \text { years of } \\
\text { age }\end{array}$} & Mean 1.05 & Mean 1.07 & .001 \\
\hline & $\mathrm{M}: \mathrm{n} 1.05$ & $\mathrm{M}: \mathrm{n} 1.07$ & \\
\hline & SD 0.04 & SD 0.05 & \\
\hline
\end{tabular}

*: at 4 years of age BMI: Body Mass Index SD: Standard deviation M : n: Median

model. Children that grow to become overweight appear to have a higher BMI at birth most likely due to a difference in weight, not in length. At four years of age, the height of children that were overweight was significantly higher than those who were not, indicating an accelerated linear growth in this group.

\section{Discussion}

This study compared the growth and development of overweight from birth to age four in children living in two Socioeconomic diverse residential areas in Gothenburg, Sweden. A significant association was found between the CHC-districts' Socioeconomic status, BMI at birth, and the development of overweight among 4-year-old children.

When comparing the two CHC units, there were several significant differences when the children were 4 years of age. There was a significantly higher proportion of children that were overweight (including obesity) in the district with lower Socioeconomic status. The mean BMISDS and subjects with high-growth velocity were also higher in this district. Furthermore, BMI at birth and CHC-district affiliation were shown to be independent determinants for BMISDS and overweight at 4 years of age.

The data in the study were obtained from two different $\mathrm{CHC}$ units, selected to include populations showing a difference in their Socioeconomic status. The official demographic and Socioeconomic data show a great difference in the distribution of these variables for the two districts (Table 1). It is likely that some changes have occurred in the population over the four-year period and this may have affected the ability to get data for $100 \%$ of the children at four-years of age. The families with lower Socioeconomic status may be more prone to move away, and the effect of this would be that our findings are likely to underestimate the real difference, even though we found significant 
differences between the two CHCs. The participation rate at the check-ups was high (94 and 96\% for CHC-dA and $\mathrm{CHC}-\mathrm{dB}$ ) suggesting that the investigated populations were representative of the 4 -year-olds of each district. Since the participation rate also was comparable for the two districts, the two populations as such are most likely to have the socio-demographic characteristics typical for their living area and thus representing different Socioeconomic subsets in the total population of four-year-olds.

An association between low Socioeconomic status and overweight in childhood is in accordance with previous studies considering factors such as mothers with low educational status [17], occupation, education, and income [4]. Among the variables obtained from the records of the $\mathrm{CHC}$ (Table 2), maternal smoking rate during pregnancy may be associated to Socioeconomic factors [18]. There was a tendency for a higher rate of reported maternal smoking during pregnancy in the district with lower Socioeconomic status $(P=.07)$. Dubois and Girard found that maternal smoking during pregnancy and low Socioeconomic status had a significant role in the development of overweight from birth to 4-5 years of age [19]

Babies that grew overweight and obese appeared to be of similar length at birth as those who did not, while their weight at birth was significantly higher, explaining the higher $\mathrm{BMI}$ at birth. In the stepwise logistic regression analysis, BMI but not weight at birth was a determinant for the BMISDS at 4 years of age. An increased relative fat mass at birth may be an explanation to these findings. Newborns with an increased fat mass have previously been shown to have higher insulin levels in their cord-blood and were found to have a greater potential to grow overweight in a followup during early childhood [20]. In a recent study of large for gestational age (LGA) newborns, similar results were found. A subgroup of LGA babies was identified as being large mainly due to increased weight. This group was, in contrast to those being large due to increased length, shown to have an increased risk for developing overweight later in life [21]. In our study, the height of children at 4 years of age was higher in the group with overweight, indicating an accelerated linear growth in children becoming overweight. This finding is in accordance with previous studies showing an increase in longitudinal growth for children with a higher BMI $[22,23]$. The balance at birth between fat mass and lean mass has also been suggested to be of crucial importance for growth, where a higher proportion of lean or muscle mass would be associated with slower growth rate [24].

Overweight children have an increased risk of becoming overweight or obese as adults [25]. The association between birth weight and adult weight suggests that there are enduring effects of the intrauterine environment on the risk for obesity later in life. Genetic, environmental and, specific maternal factors may influence the intrauterine environment to increase obesity risk [26]. Muscle activity may prevent the health hazards related to obesity in adults and older children [27]. In young children, it is rather the environment and the family that act as important determinants of physical activity, mainly by reducing sedentary behaviour. These aspects may be important to address for preventive purposes [28].
In conclusion, high BMI at birth and low Socioeconomic status, as indicated by data at the population level, were found to be independent determinants of overweight and high BMI at four years of age. Related to this was the finding that children from the district with lower Socioeconomic status had an accelerated linear growth up to four years of age. This study suggest that growth patterns early on in childhood and Socioeconomic factors play a role in the development of overweight and obesity in four-year-olds. More research is needed to understand the mechanisms and how intervention programs should be designed in order to prevent the development of overweight and obesity in children.

\section{References}

[1] World Health Organisation, "Obesity: preventing and managing the global epidemic," Report of a WHO Consultation 894, World Health Organization, Geneva, Switzerland, 2000.

[2] R. Jackson-Leach and T. Lobstein, "Estimated burden of paediatric obesity and comorbidities in Europe-part 1. The increase in the prevalence of child obesity in Europe is itself increasing," International Journal of Pediatric Obesity, vol. 1, pp. 26-32, 2006.

[3] S. Mårild, M. Bondestam, R. Bergström, S. Ehnberg, A. Hollsing, and K. Albertsson-Wikland, "Prevalence trends of obesity and overweight among 10 -year-old children in western Sweden and relationship with parental body mass index," Acta Paediatrica, vol. 93, no. 12, pp. 1588-1595, 2004.

[4] H. K. Blomquist and E. Bergström, "Obesity in 4-year-old children more prevalent in girls and in municipalities with a low socioeconomic level," Acta Paediatrica, vol. 96, no. 1, pp. 113-116, 2007.

[5] Q. He and J. Karlberg, "Prediction of adult overweight during the pediatric years," Pediatric Research, vol. 46, pp. 697-703, 1999.

[6] J. J. Reilly, E. Methven, Z. C. McDowell, et al., "Health consequences of obesity," Archives of Disease in Childhood, vol. 88, no. 9, pp. 748-752, 2003.

[7] S. R. Srinivasan, L. Myers, and G. S. Berenson, "Predictability of childhood adiposity and insulin for developing insulin resistance syndrome (syndrome $\mathrm{X}$ ) in young adulthood: the Bogalusa Heart Study," Diabetes, vol. 51, no. 1, pp. 204-209, 2002.

[8] R. Weiss, J. Dziura, T. S. Burgert, et al., "Obesity and the metabolic syndrome in children and adolescents," New England Journal of Medicine, vol. 350, no. 23, pp. 2362-2374, 2004.

[9] G. Egger and B. Swinburn, "An 'ecological' approach to the obesity pandemic," British Medical Journal, vol. 315, no. 7106, pp. 477-480, 1997.

[10] A. Sandbæk, "Children and adolescents presenting in general practice: potential for identification and intervention against overweight," Scandinavian Journal of Primary Health Care, vol. 25, no. 4, pp. 193-194, 2007.

[11] B. G. Mériaux, A.-L. Hellström, and S. Mårild, "Identification and follow-up of obesity in ten-year-old school children," International Journal of Pediatric Obesity, vol. 3, no. 2, pp. 102$108,2008$.

[12] T. Mellbin and J.-C. Vuille, "Rapidly developing overweight in school children as an indicator of psychosocial stress," Acta Paediatrica Scandinavica, vol. 78, no. 4, pp. 568-575, 1989. 
[13] T. J. Cole, M. C. Bellizzi, K. M. Flegal, and W. H. Dietz, "Establishing a standard definition for child overweight and obesity worldwide: international survey," British Medical Journal, vol. 320, no. 7244, pp. 1240-1243, 2000.

[14] J. Karlberg, Z. C. Luo, and K. Albertsson-Wikland, "Body mass index reference values (mean and SD) for Swedish children," Acta Paediatrica, vol. 90, no. 12, pp. 1427-1434, 2001.

[15] J. Karlberg, Z. C. Luo, and K. Albertsson-Wikland, "Erratum: body mass index reference values (mean and SD) for Swedish children," Acta Paediatrica, vol. 91, p. 362, 2002.

[16] http://www.goteborg.se/wps/portal.

[17] F. Rasmussen and M. Johansson, "The relation of weight, length and ponderal index at birth to body mass index and overweight among 18-year-old males in Sweden," European Journal of Epidemiology, vol. 14, no. 4, pp. 373-380, 1998.

[18] J. P. Mackenbach, I. Stirbu, A.-J. R. Roskam, et al., "Socioeconomic inequalities in health in 22 European countries," New England Journal of Medicine, vol. 358, pp. 2468-2481, 2008.

[19] L. Dubois and M. Girard, "Early determinants of overweight at 4.5 years in a population-based longitudinal study," International Journal of Obesity, vol. 30, no. 4, pp. 610-617, 2006.

[20] C. S. Yajnik, "Early life origins of insulin resistance and type 2 diabetes in India and other Asian countries," Journal of Nutrition, vol. 134, no. 1, pp. 205-210, 2004.

[21] F. Ahlsson, J. Gustafsson, T. Tuvemo, and M. Lundgren, "Females born large for gestational age have a doubled risk of giving birth to large for gestational age infants," Acta Paediatrica, vol. 96, no. 3, pp. 358-362, 2007.

[22] K. K. L. Ong, M. L. Ahmed, P. M. Emmett, M. A. Preece, and D. B. Dunger, "Association between postnatal catch-up growth and obesity in childhood: prospective cohort study," British Medical Journal, vol. 320, no. 7240, pp. 967-971, 2000.

[23] B. Heude, L. Lafay, J. M. Borys, et al., "Time trend in height, weight, and obesity prevalence in school children from Northern France, 1992-2000," Diabetes and Metabolism, vol. 29, no. 3, pp. 235-240, 2003.

[24] D. Ralt, "The muscle-fat duel or why obese children are taller?" BMC Pediatrics, vol. 6, article 33, 2006.

[25] H.-O. Mossberg, "40-year follow-up of overweight children," Lancet, vol. 2, no. 8661, pp. 491-493, 1989.

[26] R. C. Whitaker and W. H. Dietz, "Role of the prenatal environment in the development of obesity," Journal of Pediatrics, vol. 132, no. 5, pp. 768-776, 1998.

[27] K. Watts, T. W. Jones, E. A. Davis, and D. Green, "Exercise training in obese children and adolescents: current concepts," Sports Medicine, vol. 35, no. 5, pp. 375-392, 2005.

[28] A. Timperio, J. Salmon, K. Ball, et al., "Family physical activity and sedentary environments and weight change in children," International Journal of Pediatric Obesity, vol. 3, no. 3, pp. 160$167,2008$. 


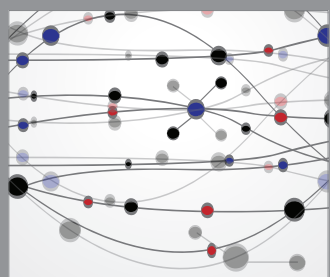

The Scientific World Journal
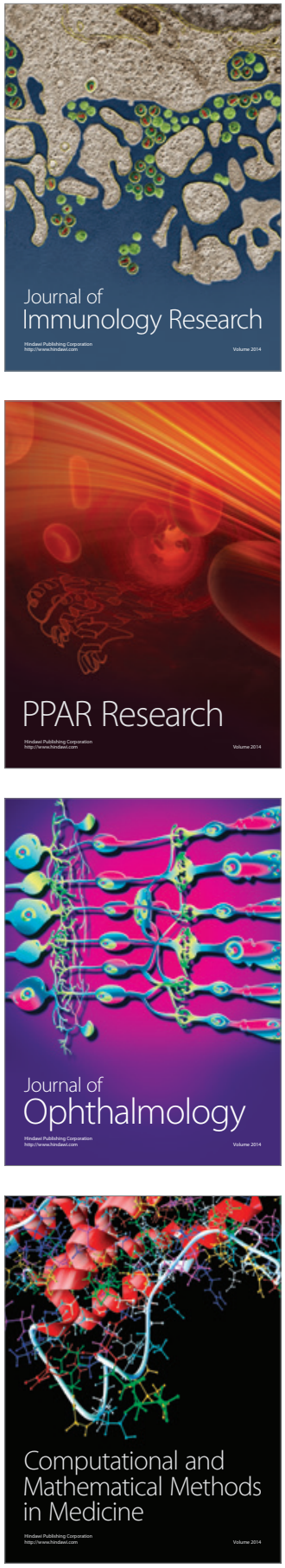

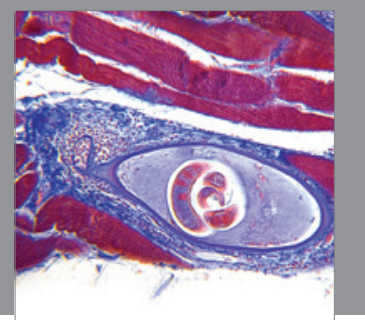

Gastroenterology

Research and Practice
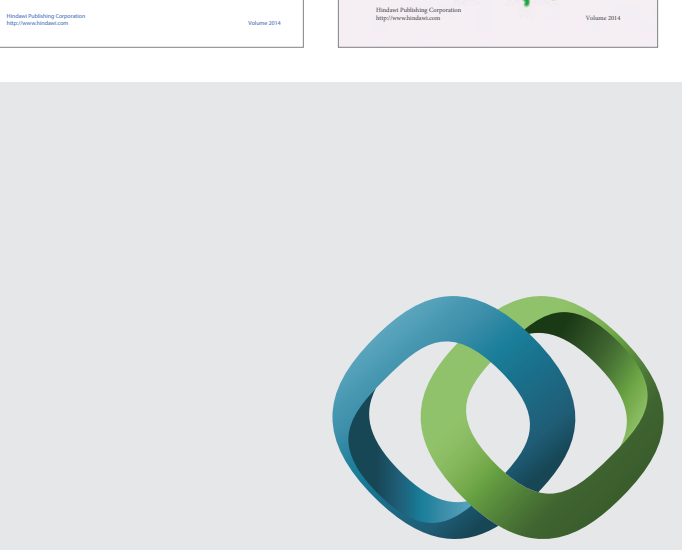

\section{Hindawi}

Submit your manuscripts at

http://www.hindawi.com
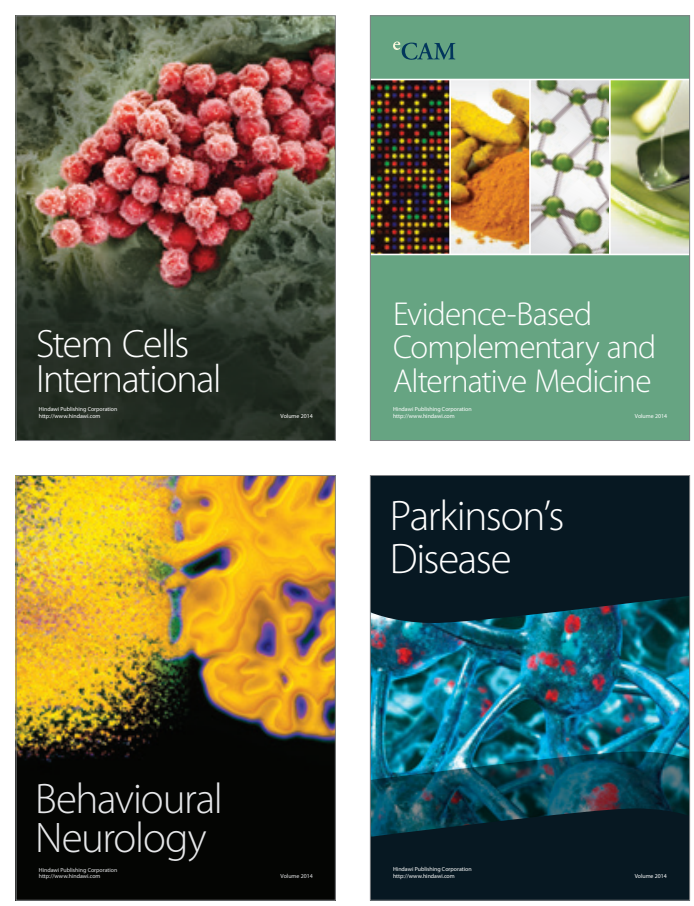



Journal of
Diabetes Research

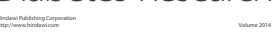

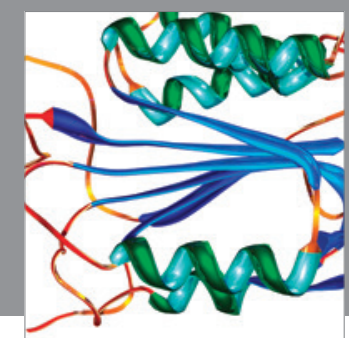

Disease Markers
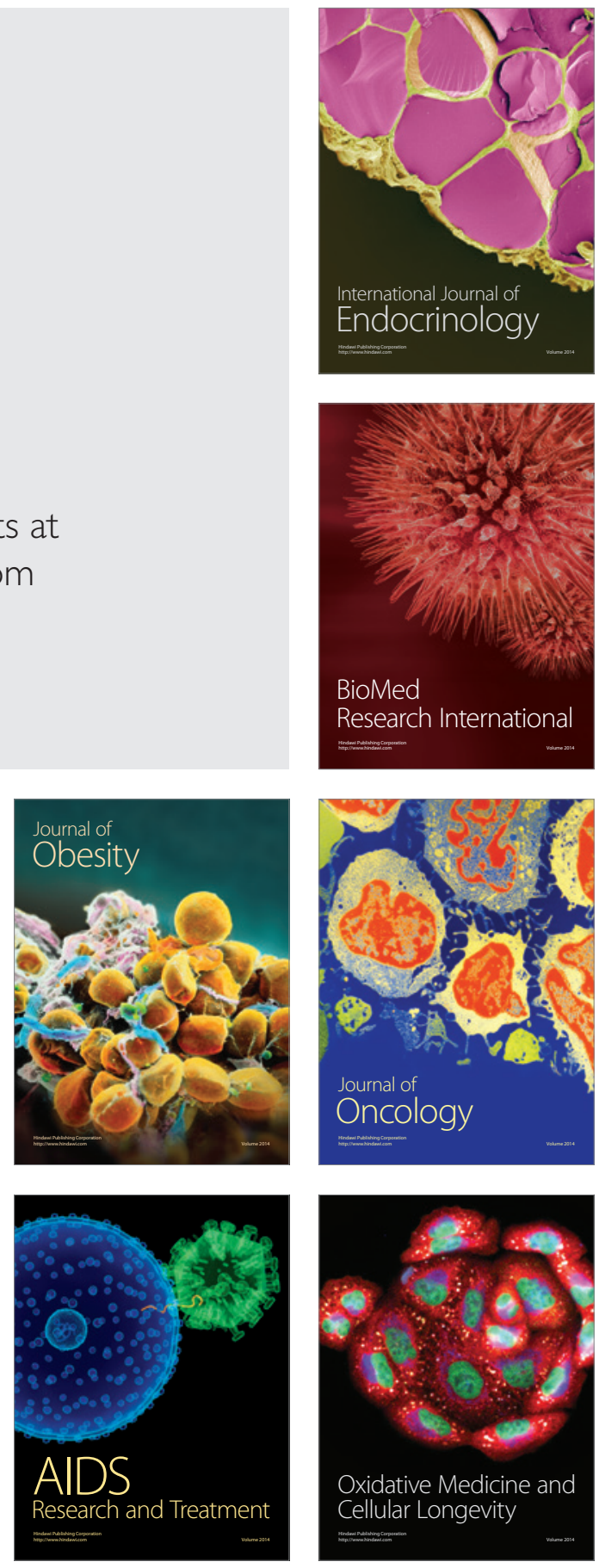